\title{
Associações entre autoeficácia docente e escolha pela docência por pós-graduandos em Engenharia ${ }^{1}$
}

\author{
Mayara da Mota Matos ${ }^{2}$ \\ Roberto Tadeu Iaochite \\ Universidade Estadual Paulista - UNESP, Rio Claro-SP, Brasil
}

\section{Resumo}

Esse estudo objetivou identificar fatores que influenciam na escolha de pós-graduandos em Engenharia pela docência no ensino superior, a autoeficácia docente e relacionar essas variáveis. Participaram 340 pós-graduandos de 33 programas de Engenharias do Brasil. Ao realizar a correlação de Pearson entre a autoeficácia docente e as dimensões da Escala de Fatores que Influenciam o Ensino, encontrou-se correlações positivas indicando que conforme aumentaram os níveis de crenças de autoeficácia docente proporcionalmente houve aumento na motivação. Esses resultados permitiram refletir sobre o papel das experiências de ensino nos programas de pós-graduação, com foco na formação de futuros professores do ensino superior.

Palavras-chave: Autoeficácia, escolha profissional, pós-graduação

\section{Abstract: Associations between teacher self-efficacy and teaching choice by graduate students in Engineering}

This study aimed to identify factors that influence the choice of graduate students in Engineering for teaching in higher education, teaching self-efficacy and to relate these variables. 340 postgraduate students from 33 engineering programs in Brazil participated. Pearson's correlation between teacher self-efficacy and the dimensions of the Factors Influencing Teaching Scale showed positive correlations, indicating that as the levels of teacher self-efficacy beliefs proportionally increased, there was an increase in motivation. These results allowed us to reflect on the role of teaching experiences in graduate programs, focusing on the training of future higher education teachers.

Keywords: Self-efficacy, professional choice, graduate training

\section{Resumen: Relaciones entre autoeficacia docente y elección de la docencia en postgraduados de Ingeniería}

Este estudio tuvo como objetivo identificar factores que influyen en la elección de la docencia en la enseñanza superior por parte de postgraduados de Ingeniería, la autoeficacia docente y relacionar esas variables. Participaron 340 postgraduados de 33 programas de Ingeniería de Brasil. Al realizar la correlación de Pearson entre la autoeficacia docente y las dimensiones de la Escala de Factores que Influyen en la Enseñanza, se encontraron correlaciones positivas, indicando que a medida que aumentaron los niveles de creencias de autoeficacia docente, proporcionalmente hubo un aumento en la motivación. Estos resultados nos permitieron reflexionar sobre el papel de las experiencias de enseñanza en los programas de postgrado, con foco en la formación de futuros profesores.

Palabras clave: Autoeficacia, elección profesional, postgrado

\footnotetext{
${ }^{1}$ Agradecemos à Universidade Federal de Alfenas pelo apoio concedido à primeira autora.

${ }^{2}$ Endereço para correspondência: Departamento de Educação, IB/UNESP, Campus de Rio Claro. Avenida 24 A, 1515, Bela Vista, 13506-900, Rio Claro, SP. E-mail: mayara.mmatos@gmail.com
} 
A expansão do Ensino Superior, indicada pelos dados do Instituto Nacional de Estudos e Pesquisas Educacionais "Anísio Teixeira" (INEP), demonstrou aumento de mais de $500 \%$ no número de cursos de graduação do país, entre 1991 e 2011. Paralelamente a esse processo, ocorreu também a expansão do sistema de pós-graduação brasileiro visando, dentre outros objetivos, formar professores de Ensino Superior para suprir a demanda desses novos cursos de graduação. Resultados apresentados no estudo de Cirani, Campanário e Silva (2015) indicaram que, no período de 1999 a 2011, o número de programas de pós-graduação no país aumentou de 2.417 para 4.660 .

Tem-se que a formação do professor de Ensino Superior no Brasil se dá por meio da pós-graduação, preferencialmente a stricto sensu, de forma que o critério de ascensão à carreira é a titulação. Entretanto, pela forma como se estrutura a pós-graduação no Brasil, inclusive no que se refere aos critérios de avaliação da mesma pela Coordenação de Aperfeiçoamento de Pessoal de Nível Superior (CAPES), a ênfase recai sobre as atividades de pesquisa, havendo pouco espaço para a discussão sobre a formação docente (Corrêa \& Ribeiro, 2013).

Embora as políticas nacionais para a pós-graduação não coloquem a docência universitária como centro da discussão, recentemente, pesquisadores de diversas áreas têm trazido questões relacionadas à docência universitária, tais como a necessidade de formação pedagógica do professor universitário, a importância dessa formação na aprendizagem dos alunos e as necessidades formativas de professores de cursos específicos (Cunha, 2006; Marini, 2013; Masetto \& Gaeta, 2013). Destacam-se, também, os estudos que compreendem a pós-graduação como lócus privilegiado da formação docente desse nível de atuação e, por isso, analisaram a estruturação dos programas e as atividades didático-pedagógicas instituídas tais como o estágio de docência (Corrêa \& Ribeiro, 2013; Matos, 2015).

Tais pesquisas, entretanto, não abordaram as questões que permeiam os motivos pelos quais estudantes de pós-graduação almejam a carreira docente no contexto universitário. Ao considerar que as atividades de pesquisa assumem um papel preponderante na pós-graduação, visto que o próprio sistema legitima a docência por meio da titulação, sem preparação específica para o magistério (Cunha, 2006), pouco se sabe sobre o significado que esses estudantes atribuem ao ensino, bem como o que os levam à escolha por essa carreira.

Nos programas de pós-graduação em Engenharia, por exemplo, se tem realizado diversas discussões a respeito do professor-engenheiro, particularmente por se tratar de uma área que apresenta altos números de evasão do curso e de retenção em disciplinas (Dallabona \& Alberti, 2016). Dessa forma, autores como Bazzo, Pereira e Von Linsigen (2000) e Reis (2009) apontaram a formação pedagógica dos professores da área como fundamental para a melhoria da qualidade dos cursos de graduação. Os autores destacaram, ainda, as mudanças no papel do professor a partir da introdução de novas tecnologias no processo educativo (Longo, 2010) e os processos de avaliação desses professores (Alves \& Enslin, 2008).

Assim, ao se identificar os fatores que influenciam na escolha pela carreira docente no Ensino Superior junto aos pós-graduandos e, nesse caso, os das Engenharias, se acredita que, para além de oferecer contribuições para essa lacuna nas pesquisas, é possível ampliar as necessárias reflexões e encaminhamentos de natureza pedagógica, face à construção de projetos nos programas de pós-graduação que objetivem a qualidade dessa formação, incluindo a dimensão pedagógica como um dos pilares fundamentais para o sucesso na preparação desse futuro professor universitário.

Para tanto, elegeu-se as relações entre as motivações para escolha de carreira e as crenças de autoeficácia docente como foco de pesquisa, já que as crenças do indivíduo sobre si mesmo - dentre elas a autoeficácia- se relacionam com diferentes tipos de valores pessoais e suas associações são preditivas de vários comportamentos, tais como o esforço despendido para realização da tarefa (Watt \& Richardson, 2015).

Como forma de conhecer os fatores ligados à escolha pela carreira docente, optou-se pelas contribuições advindas dos estudos de Watt \& Richardson (2007; 2012; 2015), os quais foram pautados na teoria de motivação da expectativa-valor de Eccles e colaboradores no início dos anos de 1980. O modelo teórico desenvolvido por Watt \& Richardson (2012) sintetiza vários fatores apontados na literatura sobre escolha de carreiras, entendendo que as autopercepções, as experiências prévias e os valores individuais influenciam na escolha pela carreira docente. A adoção deste referencial se justificou na medida em que o mesmo foi desenvolvido para explicar a escolha pela docência nos estágios iniciais desse processo (Watt \& Richardson, 2015).

O modelo considera os diferentes fatores motivacionais utilizados para a escolha de carreira: a análise da percepção pessoal de capacidade para a realização das tarefas necessárias à profissão, o valor atribuído à profissão e o custo da profissão para o indivíduo (Watt \& Richardson, 2012). Esses fatores estão dispostos em 5 dimensões, conforme exposto na Figura 1: influências de socialização, percepções sobre a tarefa docente, autopercepções, valores e segunda opção de carreira. 


\section{Escolha de carreira docente}

Discussão social

Experiências prévias de ensino e aprendizagem

Influências sociais

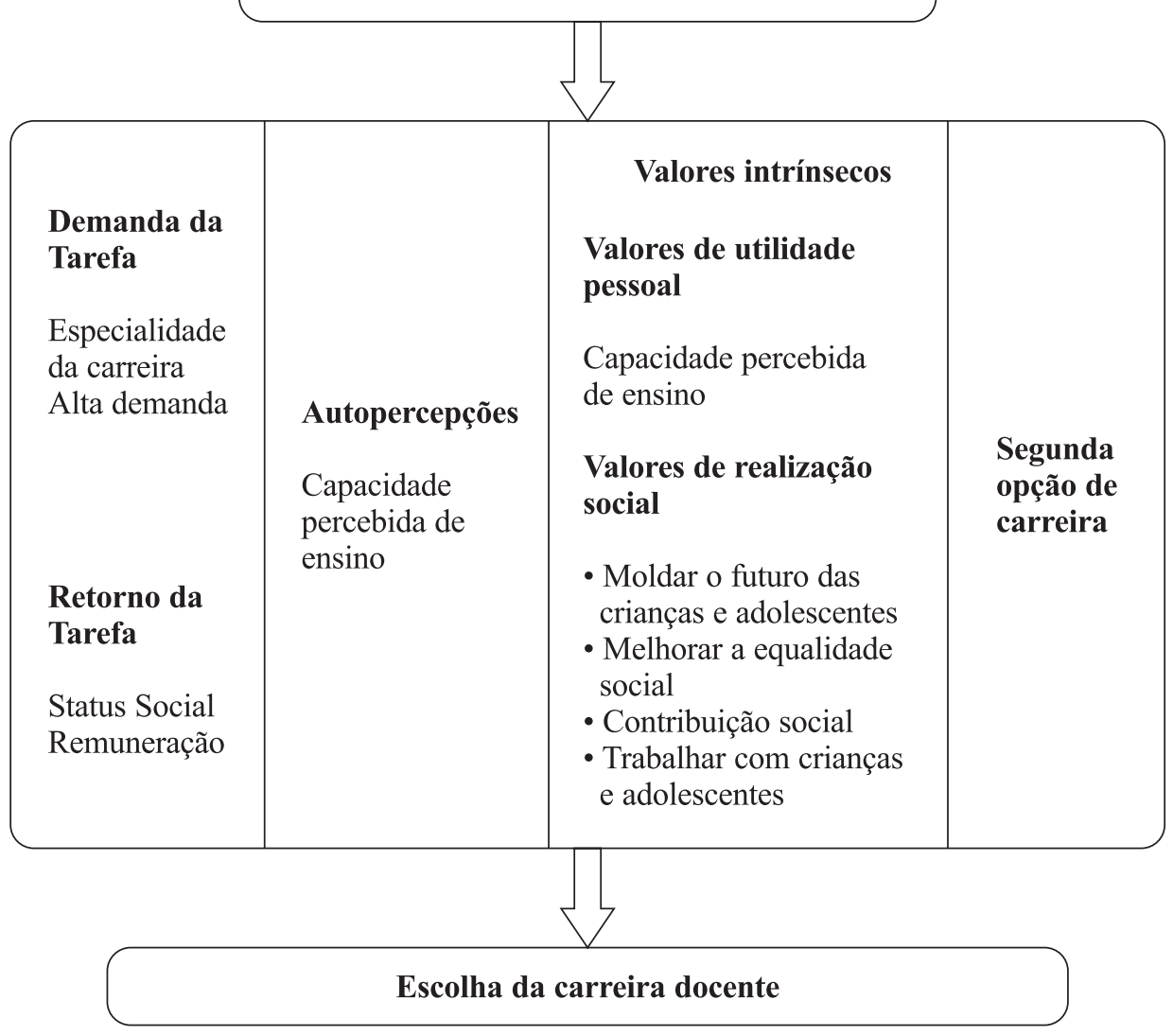

Figura 1. Modelo teórico FIT-Choice de Watt \& Richardson (2012) sobre fatores motivacionais ligados à escolha pela carreira docente

Em síntese, o modelo proposto entende a dimensão das influências de socialização como sendo as experiências anteriores, tanto ao longo da escolarização como discentes ou como docentes (em caso de ter havido experiências dessa natureza), bem como as influências sociais de incentivo e desencorajamento à escolha pela docência. A dimensão sobre as percepções da tarefa docente se refere às exigências da profissão, como o desgaste emocional e os benefícios proporcionados pela carreira, como o reconhecimento social e a remuneração.

A dimensão ligada às autopercepções diz respeito ao conjunto de percepções sobre as competências necessárias para ensinar. Já, a dimensão dos valores é entendida como o que se considera desejável para seguir e se sentir realizado com a escolha pela carreira (Watt \& Richardson, 2015), dividindo-se em três classes: os intrínsecos, os de utilidade pessoal e os de realização social. Por fim, a dimensão correspondente à segunda opção de carreira representa a possibilidade de a escolha pela docência ter se dado em função da não aprovação em outro curso ou programa tido como primeira ou principal escolha pessoal.

Destaca-se ainda que o modelo proposto e resumidamente apresentado se constitui a partir da síntese de estudos de levantamento sobre a docência realizados em países diversos, indicando os motivos apontados com mais frequência e classificando-os de acordo com a teoria da expectativa-valor (Watt \& Richardson, 2015) e que foi considerado um dos maiores avanços da última década no que se refere a pesquisas empíricas sobre a escolha da docência como carreira (Heinz, 2015), o que justifica sua adoção.

Outros estudos utilizando o mesmo modelo teórico e instrumento foram realizados em diversos países e 
obtiveram resultados consistentes. Na Turquia, Kilinç, Watt e Richardson (2012) avaliaram 1577 professores do ensino primário e secundário e encontraram que os motivos mais apontados para a escolha da carreira docente foram os valores de realização social "Contribuição social", "Trabalhar com crianças e adolescentes" e "Segurança profissional", o que indica que os motivos mais importantes para esses participantes estão relacionados tanto a contribuição social que o professor pode realizar quanto com a segurança oferecida pela profissão, em termos de estabilidade e benefícios econômicos, por exemplo. Já em estudo com participantes do ensino primário e secundário de quatro países - Estados Unidos da América, Austrália, Noruega e Alemanha - Watt e Richardson (2012) encontraram que, em todos os países, os motivos mais indicados pertenciam à dimensão valores intrínsecos, sendo os maiores escores em "Capacidade percebida de ensino" e "Contribuição social", ou seja, os fatores que levam os participantes desses países a escolherem a docência estão mais relacionados às percepções de capacidade individual e à vontade de contribuir com a sociedade. Nesse sentido, é preciso considerar as diferenças políticas, sociais e econômicas dos países onde as pesquisas foram realizadas, já que essas podem afetar as motivações individuais: em países que vivem um período recessão econômica, por exemplo, é natural que aspectos como a segurança profissional proporcionada pela carreira docente sejam uma forte motivação para os participantes (Heinz, 2015).

Se por um lado, é importante o conhecimento sobre os fatores motivacionais que influenciam a escolha pela carreira docente, considerando os argumentos já citados, por outro, é fundamental que os futuros professores se percebam capazes de exercer a docência nesse contexto, a despeito das demandas e desafios nele presentes. De acordo com Bandura (1997), além de ter as habilidades necessárias para realizar uma determinada tarefa, é fundamental que a pessoa acredite ser capaz de realizá-la (autoeficácia) e são as suas autopercepções que influenciarão em suas tomadas de decisão. Dessa forma, pessoas com maiores níveis de autoeficácia poderão atribuir seus fracassos à falta de esforço e persistirem mais diante das tarefas, propor objetivos a partir dos resultados esperados de determinadas ações e estabelecer metas mais desafiadoras, se motivando para alcançá-las em busca da satisfação pessoal (Azzi \& Polydoro, 2006).

No que se refere à escolha de carreira, as crenças de autoeficácia influenciam nos processos de seleção realizados pelos indivíduos, já que as pessoas tendem a escolher cursos de ação nos quais se sintam confortáveis e para os quais entendam que possuem as capacidades necessárias. Dessa forma, as crenças de autoeficácia docente podem ser definidas como "um julgamento que o professor faz acerca de suas próprias capacidades para atingir resultados desejados de engajamento e aprendizagem dos alunos, mesmo entre aqueles alunos difíceis ou desmotivados" (Tschannen-Moran \& Woolfolk Hoy, 2001, p. 783). De acordo com Bandura (1997) essas crenças são constituídas a partir de quatro fontes de informação: as experiências diretas, as experiências vicárias, a persuasão social e os estados fisiológicos afetivos.

As experiências diretas, consideradas as mais influentes, tratam-se das situações vivenciadas pelo indivíduo em um determinado domínio e que lhe permitem avaliar seu desempenho e construir crenças sobre as suas capacidades. As experiências vicárias referem-se às oportunidades de observação das experiências de outras pessoas. O professor pode observar, por exemplo, diferentes modelos apresentando novas metodologias de ensino pessoalmente ou por meio de vídeos instrucionais e, a partir dessa observação, avaliar sua capacidade de colocar essas metodologias em prática (Matos, 2015).

A terceira fonte é a persuasão social e diz respeito à influência de outras pessoas nas crenças de autoeficácia que, normalmente, se dão de maneira verbal, as quais tem mais influência quando recebida de fontes confiáveis e baseadas no desempenho real do indivíduo, alerta Bandura (1997). Elogios e feedback podem influenciar na percepção de capacidade para realizar determinada atividade.

A quarta e última fonte trata-se de estados fisiológicos e afetivos, que dizem respeito às reações psicofisiológicas do indivíduo diante de uma determinada tarefa. Bandura (1997) indica que essas reações influenciam os julgamentos que o indivíduo realiza sobre sua capacidade de realizar a tarefa, sendo que indivíduos mais autoeficazes tendem a interpretar essas reações como o nível de ativação do organismo para realizá-las, enquanto aqueles com crenças menos consolidadas podem entendê-las como medo ou dúvida a respeito de sua capacidade. Destaca-se ainda que essas fontes não são automaticamente assimiladas pelo indivíduo, mas dependem do processamento cognitivo das informações que ele seleciona, bem como da integração dessas.

Estudos sobre a autoeficácia docente de professores do Ensino Superior têm sido realizados em diferentes países, reafirmando a importância do constructo. $\mathrm{Na}$ Finlândia, Postareff, Lindblom-Ylanne e Nevgi (2007) realizaram estudo visando compreender de que forma o treinamento pedagógico de professores universitários influenciava suas crenças de autoeficácia, encontrando que quanto maior o tempo de treinamento realizado, maiores os níveis da crença. Rocha (2009), em estudo com professores brasileiros, encontrou que os mesmos 
possuíam níveis elevados de autoeficácia docente. Ainda no Brasil, Bernadini (2017) correlacionou as crenças de autoeficácia docente com a síndrome de Burnout, encontrando associações significativas que indicam que essas crenças podem atuar como fator protetivo contra o adoecimento docente.

A literatura sobre crenças docentes tem indicado a importância de características pessoais no desenvolvimento de motivações, percepções e no comprometimento de professores com o seu trabalho. Desta forma, ao problematizarmos a escolha pela carreira docente por estudantes de pós-graduação, entendeu-se haver necessidade de dialogar com as crenças de autoeficácia docente, uma vez que tão importante quanto identificar fatores que possibilitem ampliar a discussão sobre a escolha da carreira docente para o contexto universitário, há que se identificar, também, em que medida essa escolha pode estar associada com o quanto esses futuros professores acreditam que poderão realizar o ensino, considerando os desafios presentes no cotidiano da prática pedagógica no ensino superior.

Como indicam Lent, Brown e Hackett (1994), pode-se compreender as crenças de autoeficácia como motivadoras na escolha e na permanência em uma determinada profissão, já que de forma geral, as pessoas se interessam por carreiras nas quais se sintam competentes. Nesse sentido, assumiu-se como um dos objetivos deste estudo mensurar as crenças de autoeficácia docente dos participantes e correlacioná-las aos resultados relacionados às suas motivações e percepções da docência.

Buscando responder as questões "quais fatores influenciam na escolha pela carreira docente no Ensino Superior por pós-graduandos em Engenharia?"; "como estes percebem a docência no Ensino Superior?" e " existem associações entre as crenças de autoeficácia docente dos pós-graduandos ligados à escolha pela docência no Ensino Superior?", definiu-se como objetivos de pesquisa: (a) identificar os fatores que levam os pós-graduandos em Engenharia a escolher a carreira docente no Ensino Superior; (b) identificar percepções dos pós-graduandos sobre a carreira docente; (c) mensurar o nível de autoeficácia para a docência e, (d) analisar possíveis associações entre a escolha e a percepção pela carreira docente com as crenças de autoeficácia para o exercício da docência no contexto universitário.

\section{Método}

Trata-se de um recorte da pesquisa de mestrado da primeira autora. Este trabalho consiste em uma pesquisa quantitativa e exploratória.

\section{Participantes}

A amostra foi composta por 340 estudantes de 33 programas de pós-graduação stricto sensu de instituições públicas da grande área de Engenharias, localizados nas regiões Sudeste e Sul do Brasil. Essas regiões foram escolhidas pela por serem expoentes em termos de quantidade de programas de pós-graduação no país, bem como por serem consideradas como centros de disseminação de formação qualificada para as demais regiões (Brasil, 2016). A maioria dos pós-graduandos era do sexo masculino (58.2\%), estudante em nível de mestrado (66.8\%), com faixa etária média de 30.8 anos, $87.4 \%$ se graduaram em cursos de bacharelado, $45.6 \%$ não tinha nenhum tipo de experiência prévia com a docência, $32.6 \%$ atuavam como professores no período da coleta de dados e $85.9 \%$ pretendiam ser professores do Ensino Superior.

\section{Instrumentos}

Utilizou-se para a coleta de dados três instrumentos: um questionário sobre características pessoais $\mathrm{e}$ acadêmicas dos participantes, a Escala de Fatores que Influenciam a Escolha pelo Ensino (EFIEE) (Adaptada de Watt \& Richardson, 2012) e a Escala de Autoeficácia de Professores (EAED) (Polydoro, Winterstein, Azzi, Carmo, $\&$ Venditti Junior, 2004).

Aplicou-se o questionário com o objetivo de conhecer as características pessoais e de formação acadêmica dos participantes, visando correlacioná-las com os resultados do segundo instrumento. Trata-se de um instrumento desenvolvido para essa pesquisa a partir de indicações da literatura e composto por 26 itens.

A EFIEE é composta de 56 itens e trata-se da versão em português da Factors Influencing Teaching Choice - FIT - Choice Scale, que nas análises fatoriais realizadas para este estudo se manteve com duas dimensões: Motivação $(\alpha=0,91)$ e Percepção $(\alpha=0,76)$.

A dimensão Motivação objetiva avaliar os motivos que levaram os participantes a escolher a docência no Ensino Superior. Sob o título "Eu escolhi ser professor do Ensino Superior em Engenharia, porque..." são relacionadas 37 proposições sobre tempo para a família, contribuição para a sociedade e remuneração. Nessa dimensão, a escala Likert varia de 1 (sem importância alguma) a 7 (extremamente importante), em itens tais como "Ser professor do Ensino Superior em Engenharia vai me permitir beneficiar a sociedade diminuindo as desigualdades" e "As horas de trabalho irão se encaixar com as responsabilidades de se ter uma família". 
A dimensão Percepção avalia as crenças e percepções dos participantes sobre a docência, bem como a satisfação com a escolha pela carreira. Essa dimensão é constituída por 13 itens nos quais os participantes expressam seu grau de concordância, sendo 1 (discordo totalmente) e 7 (concordo totalmente), com afirmações a respeito da profissão docente, tais como "Ser professor do Ensino Superior em Engenharia requer altos níveis de conhecimento" e 6 itens relacionados à decisão pela docência, por exemplo, "Eu estou satisfeito com minha escolha de ser professor do Ensino Superior em Engenharia".

Para mensurar as crenças de autoeficácia docente dos participantes utilizou-se a Escala de Autoeficácia de Professores, validada por Polydoro, Winterstein, Azzi, Carmo e Venditti Jr. (2004). Trata-se de um instrumento Likert de 6 pontos sendo a pontuação mínima de 1 a qual representa "pouco" e a máxima de 6 pontos que significa "muito", com 24 itens distribuídos em duas dimensões: intencionalidade da ação docente e manejo de classe. Os valores de alfa de Cronbach $(\alpha=0.94)$ obtidos no estudo indicam a consistência interna de seus itens, tanto na escala global quanto nas dimensões Intencionalidade da ação docente $(\alpha=0.90)$ e Manejo de classe $(\alpha=0.86)$. A dimensão da Intencionalidade da ação docente avalia a intenção do professor de mediar o processo de ensino, sendo um exemplo de item "Quanto você pode avaliar a compreensão dos alunos(as) sobre o que ensinou?". Já a dimensão do Manejo de classe avalia a confiança que o professor tem em sua capacidade de gerenciar a sala de aula, incluindo o engajamento dos alunos em seu processo de aprendizagem. Um exemplo de item dessa dimensão é: "Quanto você pode fazer para lidar com os alunos(as) mais difíceis?"

\section{Procedimentos ético, de coleta e análise dos dados}

A pesquisa foi submetida à apreciação ética e aprovada sob o sob o número do Certificado de Apresentação para Apreciação Ética 33737914.9.0000.5465, e todos os participantes preencheram o Termo de Consentimento Livre e Esclarecido. A partir do censo da Pós-Graduação de 2012, foram encontrados 178 programas de pós-graduação acadêmicos em Engenharia. Contatou-se os coordenadores por email, solicitando-se aos mesmos que fizessem a divulgação da pesquisa ao pós-graduandos. Aplicou-se os instrumentos online por meio da ferramenta "Google Forms". Tal escolha deveu-se à possibilidade de ampliar o número de pós-graduandos atingidos, bem como pelas facilidades apresentadas pelo aplicativo, já que esse tabula parcial e automaticamente os dados coletados. O retorno foi de 18,5\% (estudantes de 33 programas). Realizou-se a análise dos dados por meio de estatística descritiva e inferencial, utilizando-se o software Statistical Package for the Social Sciences (SPSS), versão 22 para Windows.

\section{Resultados e Discussão}

Procurou-se discutir os resultados a partir dos maiores e menores escores encontrados, com particular ênfase para aqueles com maior destaque na literatura. Com relação à dimensão "Motivação" da EFIEE, o fator com maior escore foi "Experiências prévias de ensino e aprendizagem" $(M=5.41)$, compreendido como o fator que avalia as experiências dos participantes em seu processo de escolarização, particularmente durante a graduação, em itens tais como "Eu tive professores inspiradores na graduação". É possível aventar, por exemplo, que o contato prévio com a docência, ainda no papel de estudante, durante o processo de socialização (Soares \& Cunha, 2010), contribua para a valorização dessas experiências, em especial, quando tais experiências são interpretadas como significativas pelos aprendizes. Os estudos de Richardson e Watt (2006) e de Heinz (2015) também confirmaram esse fator como relevante para a escolha da carreira docente.

Os fatores "Contribuição social" $(M=5.19)$, composto por itens referentes à importância de beneficiar a sociedade, como "Ser professor do Ensino Superior em Engenharia vai me permitir beneficiar a sociedade diminuindo as desigualdades"; "Trabalhar com alunos do Ensino Superior", com itens como "Eu quero um trabalho que envolva trabalhar com futuros profissionais na área de Engenharia" e "Moldar o futuro dos alunos do Ensino Superior" que avalia a relevância da possibilidade de influenciar as gerações futuras, tais como "Ser professor do Ensino Superior em Engenharia irá me ajudar a ter influencia nas futuras gerações de profissionais da área", obtiveram, respectivamente, médias de 5.16 e 5.04 pontos. Esses fatores estão ligados à competência altruística, sendo a carreira docente ligada ao trabalho social, oferecendo suporte aos alunos. Estudos relacionados com a atratividade pela docência na Educação Básica, por exemplo, têm revelado esse fator como altamente significativo para aqueles que almejam essa carreira, como apontado no estudo de Tartuce, Nunes e Almeida (2010), bem como os de Heinz (2015) e König e Rothland (2012).

Já os fatores com menores escores para essa dimensão foram "Segunda opção de carreira" $(M=2.35)$ e "Influências sociais" $(M=3.99)$. Ao atribuírem menor valor para esses fatores, os participantes acreditaram que escolher a docência universitária como profissão pouco tem a ver com a impossibilidade de seguir a carreira de 
engenheiro ou mesmo que essa escolha tenha sido influenciada pelos amigos e ou família. Esses resultados concordaram com os achados de Akar (2012) e Kilinç et al. (2012) e podem ser interpretados como positivos ao se analisar pelo lado da certeza da escolha pela docência como futura carreira profissional. Estudos ligados ao contexto universitário são escassos acerca da identificação desses fatores que merecem ser investigados como forma de contribuir para as discussões sobre a atratividade pela docência nesse contexto.

A escolha pela docência como primeira opção pelos participantes do estudo também pode estar ligada ao que Pinto e Oliveira (2010) indicaram em seu estudo a respeito da valorização da carreira universitária na área das Engenharias. Segundo os autores, a área passou por reestruturações que a tornaram mais atrativa, particularmente ao considerar o aumento do incentivo à realização de pesquisas nas universidades e a implementação do regime de dedicação exclusiva, o que ocasionou a migração de muitos engenheiros de empresas do setor privado para as universidades públicas.

Os resultados ligados à dimensão "Percepção" indicaram o fator "Especialidade da carreira" com o maior escore $(M=6.16)$ e o fator "Dissuasão social" com o menor escore $(M=2.53)$. Isso significa que os participantes entenderam a carreira docente no contexto universitário como altamente especializada e exigente em termos de conhecimentos, já que a maior pontuação se deu item "Ser professor no ensino superior em Engenharia requer altos níveis de conhecimento" $(M=6.26)$.

Observou-se, ainda, que os participantes parecem não se importar com a opinião dos outros sobre a escolha pela docência. A média do fator "Dissuasão social" foi relativamente baixa $(M=2.53)$, o que reflete, mais uma vez, a certeza da escolha. Estudos já citados anteriormente (Heinz, 2015; Watt et al., 2012) também encontraram escores mais baixos para esses fatores. No Brasil a docência no contexto universitário, mesmo sofrendo os impactos do baixo investimento em políticas e distribuição de recursos para a educação, ainda carrega um status diferenciado em relação às condições de trabalho e salário, quando comparada com o mesmo trabalho em outros níveis da educação (Matos, 2015) o que pode justificar a pouca dissuasão social sofrida.

Em síntese, é possível destacar que as razões da escolha pela docência, segundo os participantes, estiveram ligadas às experiências da socialização no âmbito acadêmico, bem como pelo elevado valor social atribuído à carreira. A convicção dessa escolha parece ter sido reforçada pelos baixos escores atribuídos à opinião externa de amigos e familiares.
Identificar as razões pela escolha e conhecer as demandas ligadas à futura profissão podem ser insuficientes se o futuro profissional não acredita que terá a competência necessária para agir diante das demandas e dos desafios advindos dessa carreira. Dito de outra forma, acreditar nas próprias capacidades para obter os resultados esperados e realizar bem a profissão que se almeja (no caso a docência universitária) é fundamental para que haja compromisso e satisfação em cumprir com tais objetivos. A crença de autoeficácia docente oferece, parcialmente, indicativos a respeito dessa autoavaliação.

Como encontrado na literatura sobre docência na Educação Básica, os escores acerca da autoeficácia docente dos participantes foi relativamente alta $(M=4.46$; \pm 0.69 ), resultado semelhante aos encontrados em estudos já citados, onde o valor médio da autoeficácia docente total tem sido alto (Rocha, 2009; Bernardini, 2017). Quando analisados a partir de suas dimensões, os escores se mantém altos, em especial, para a "Intencionalidade da ação docente" $(M=4.51 ; \pm 0.70)$. Esses resultados são importantes quando se conhece os prováveis efeitos que a elevada autoeficácia pode imprimir nas práticas de ensino propriamente ditas e mesmo no desempenho acadêmico dos estudantes. Entretanto, é mister apontar que esses números representam apenas uma possibilidade. $\mathrm{O}$ investimento na carreira, a formação profissional de qualidade, a supervisão adequada podem, da mesma forma, trazer consequências positivas na direção da carreira escolhida. Por estar fortemente associada à dimensão motivacional, a autoeficácia pode afetar a construção das expectativas, a atribuição e a quantidade do esforço que se dispende, bem como a seleção dos objetivos a perseguir e dos cenários que se imaginam sendo enfrentados (Bandura, 1997).

Finalmente, ao investigar possíveis associações entre a crença de autoeficácia docente e os fatores motivacionais, se encontrou correlações positivas e moderadas, indicando que, conforme aumentou o escore da autoeficácia houve, proporcionalmente, aumento nos escores dos fatores motivacionais. Embora de magnitudes diferentes, isso foi encontrado com os fatores da dimensão "Motivação" da EIFEE. Entre eles: "Contribuição social" $(r<0.314)$, "Capacidades percebidas de ensino" $(p<0.436)$, "Trabalho com alunos de ensino superior" $(r<0.360)$ e "Moldar o futuro de alunos do ensino superior" $(r<0.314)$, conforme pode ser observado da Tabela 2. Ainda nessa Tabela, é possível observar as correlações positivas entre os fatores da dimensão "Percepção" da EIFEE com a AED para os fatores: "Satisfação com a escolha" $(r<0.303)$ e "Especialidade da carreira" $(r<0.259)$. 
Tabela 1

Escores dos fatores que mais e menos influenciaram a escolha pela docência como carreira profissional, a autoeficácia total e por dimensões

\begin{tabular}{lc}
\hline \multicolumn{1}{c}{ Fatores } & Média (desvio-padrão) \\
\hline MOTIVAÇÃO & \\
Segunda opção de carreira & $2.35(1.10)$ \\
Influências sociais & $3.99(1.94)$ \\
Família & $4.29(1.73)$ \\
Segurança profissional & $4.72(1.65)$ \\
Capacidades percebidas de ensino & $5.03(1.31)$ \\
Moldar o futuro de alunos do Ensino Superior & $5.04(1.50)$ \\
Trabalho com alunos de Ensino Superior & $5.16(1.53)$ \\
Contribuição social & $5.19(1.47)$ \\
Experiências prévias de ensino e aprendizagem & $5.41(1.48)$ \\
PERCEPÇ̃̃O & \\
Dissuasão social & \\
Remuneração & $2.53(1.48)$ \\
Status social & $4.13(1.50)$ \\
Alta demanda & $4.43(1.36)$ \\
Satisfação com a escolha & $4.52(1.29)$ \\
Especialidade da carreira & $5.03(1.43)$ \\
AUTOEFICÁCIA DOCENTE TOTAL & $6.16(0.94)$ \\
Intencionalidade da ação docente & $4.46(0.69)$ \\
Manejo da sala de aula & $4.51(0.70)$ \\
\hline
\end{tabular}

Média (desvio-padrão)

Tabela 2

Correlação de Pearson da autoeficácia docente com os fatores da EFIEE

\begin{tabular}{lccc}
\hline \multirow{2}{*}{ EFIEE } & \multicolumn{2}{c}{ EAD } \\
\cline { 2 - 4 } & EAD Total & $\begin{array}{c}\text { Intencionalidade } \\
\text { da ação docente }\end{array}$ & $\begin{array}{c}\text { Manejo em sala } \\
\text { de aula de aula }\end{array}$ \\
\hline MOTIVAÇÃO & $0.326^{* *}$ & $0.322^{* *}$ & $0.305^{* *}$ \\
Contribuição social & $0.314^{* *}$ & $0.310^{* *}$ & $0.296^{* *}$ \\
Segurança profissional & -0.045 & -0.037 & -0.052 \\
Experiências prévias de ensino e aprendizagem & $0.283^{* *}$ & $0.283^{* *}$ & $0.261^{* *}$ \\
Capacidades percebidas de ensino & $0.436^{* *}$ & $0.406^{* *}$ & $0.441^{* *}$ \\
Influências sociais & $0.122^{*}$ & $0.132^{*}$ & 0.099 \\
Família & 0.075 & 0.076 & 0.067 \\
Trabalho com alunos de ensino superior & $0.360^{* *}$ & $0.363^{* *}$ & $0.328^{* *}$ \\
Segunda opção de carreira & $-0.156^{* *}$ & $-0.154^{* *}$ & $-0.147^{* *}$ \\
Moldar o futuro de alunos do ensino superior & $0.314^{* *}$ & $0.311^{* *}$ & $0.294^{* *}$ \\
PERCEPÇÃO & $0.127^{*}$ & $0.129^{*}$ & $0.115^{*}$ \\
Status social & 0.057 & 0.060 & 0.047 \\
Satisfação com a escolha & $0.303^{* *}$ & $0.269^{* *}$ & $0326^{* *}$ \\
Dissuasão social & -0.093 & -0.074 & $-0.111^{*}$ \\
Remuneração & 0.018 & 0.030 & -0.001 \\
Alta demanda & -0.060 & -0.055 & -0.063 \\
Especialidade da carreira & $0.259^{* *}$ & $0.255^{* *}$ & $0.243^{* *}$ \\
\hline
\end{tabular}

$* p<0.05 ; * * p<0.01$. Fonte: Matos (2015) 
A associação positiva entre autoeficácia docente e fatores motivacionais da EIFEE era, por teoria, esperada. O modelo proposto pela EIFEE está centrado na teoria de motivação de expectativa-valor e este, segundo Bandura (1997), expressa que quanto maior a expectativa de que dado comportamento pode assegurar resultados específicos, sendo esses resultados altamente valorizados pelo indivíduo, maior será a motivação para realizar tal comportamento. Bandura adicionou, ainda, que antecipar as consequências de um dado comportamento somente é possível quando se tem, antes disso, condições pessoais para realizá-lo. Dito de outra forma, "o potencial motivador das expectativas de resultados é parcialmente governado pelas crenças de capacidade pessoal" (Bandura, 1997, p. 126).

Há, pois, em teoria, uma relação positiva entre antecipar resultados de uma ação futura (escolha pela carreira docente universitária, os resultados advindos dessa escolha e a valorização dessa carreira) e o quanto se percebe capaz para agir diante desse cenário antecipado. Os fatores que apresentaram índices de correlação positiva e acima de .30 , por exemplo, foram aqueles que se relacionam com os fatores altruísmo, satisfação com a escolha e competência na tarefa, os quais estão ligados, de certa forma, com a realização pessoal e a possibilidade de agir nessa direção, respectivamente. Os estudos já citados de Heinz (2015) e König e Rothland (2012) ao investigarem estudantes e professores em formação para a docência encontraram resultados semelhantes sobre esses fatores. Novamente, Bandura (1997) explicou que algumas das recompensas mais valorosas são decorrentes de atividades que trazem autossatisfação pessoal, uma vez que pessoas agem sobre as crenças do que elas podem fazer, tanto quanto pelos efeitos dessas ações.

\section{Considerações finais}

A identificação dos fatores que levam à escolha da docência como carreira profissional tem sido contemplada por estudos em diferentes contextos e culturas, especialmente no âmbito da formação de professores para a Educação Básica (Heinz, 2015). O presente estudo objetivou investigar esses fatores, junto aos estudantes de pós-graduação na área das engenharias no contexto brasileiro. Atrelado a isso, buscou ainda investigar a crença de autoeficácia docente e possíveis associações entre os fatores motivacionais da escolha pela docência e a crença de autoeficácia docente.

Entende-se que identificar os fatores que influenciam a escolha pela carreira docente no ensino superior docente nas engenharias pode subsidiar a formulação de políticas públicas de atração e retenção de professores qualificados para a docência, conforme apontam Watt e Richardson (2007). Nesse sentido, os resultados encontrados evidenciam a importância dos fatores ligados às experiências anteriores de ensino e aprendizagem, bem como a dimensão social da tarefa de ensinar.

No que se refere especificamente às experiências anteriores, conforme apontado por Cunha (2006), entende-se como fundamental, destinar atenção às experiências vivenciadas durante a formação dos pós-graduandos como forma de estimulá-los a eleger a carreira docente. Ressalta-se, ainda, que a influência das experiências anteriores na autoeficácia docente exige uma reflexão a respeito do processo ensino-aprendizagem desde o ingresso na vida escolar, já que traz implicações importantes para o sentimento de capacidade dos estudantes em suas próprias capacidades para ter bom desempenho nos estudos e para se tornarem professores, caso escolham essa carreira profissional.

Considerando ainda que tanto a autoeficácia docente quanto a escolha pela carreira docente são influenciadas por essas experiências prévias, cabe uma reflexão dos professores que atuam nos programas de pós-graduação a respeito do modelo que gostariam de oferecer aos seus alunos. Nesse sentido, várias questões podem ser levantadas: qual o conceito de ensino e aprendizagem os professores gostariam que seus alunos assimilassem? Será que a atuação na sala de aula da pós-graduação estimula os alunos a compreenderem o ensino para além da reprodução de técnicas e modelos ultrapassados? Quais competências e habilidades os pós-graduandos perceberão a partir das experiências de ensino e que poderão ser importantes para se pensar o exercício da docência universitária? Qual tem sido a atuação das instituições universitárias, em especial da pós-graduação, em relação ao papel de bem formar os futuros professores universitários para além da pesquisa, considerando que o ensino, a pesquisa, a extensão e, mais recentemente, a gestão, fazem parte da rotina profissional nesse contexto?

A discussão posta na literatura sobre a formação do professor universitário reforça, para além das habilidades necessárias à pesquisa e à extensão universitária, o desenvolvimento de competências pedagógicas (Masetto \& Gaeta, 2013), sendo estas capazes de promover junto aos pós-graduandos as capacidades de planejar, executar, avaliar e refletir sobre a própria prática de ensinar. É preciso então que os programas de pós-graduação proporcionem espaços para que seus alunos vivenciem situações de ensino e de reflexão sobre a sua prática pedagógica, oportunizando vivências para além das atividades de pesquisa, as quais de maneira geral, já se encontram disseminadas. 
Quando se compreende o quanto esses aspectos podem influenciar a crença daqueles que estão sentados nos bancos da pós-graduação com o desejo de se tornar professores universitários, amplia-se a responsabilidade do professor da pós-graduação. Urge que os pós-graduandos possam aprender com modelos que reconheçam o valor da pesquisa, do ensino e da extensão como relação interdependente, uma vez que serão chamados a partilhar dessa compreensão.

Os resultados indicam ainda a influência positiva das dimensões ligadas às capacidades de ensino e experiências anteriores nas crenças de autoeficácia docente, de forma que se estabelece uma relação onde as crenças de autoeficácia estão associadas com os motivos assumidos para escolha da docência no Ensino Superior.

Conforme já apontado anteriormente, não foi localizado na literatura até o presente momento estudos que tivessem empregado o modelo teórico do FIT-Choice em associação com as crenças de autoeficácia junto aos estudantes de pós-graduação em engenharia ou qualquer outra área especializada. Nesse sentido, ainda que se reconheça que os índices de correlação foram baixos, se abre a possibilidade de investigar essa relação dada não apenas por uma explicação teórica, mas motivada pelas implicações educacionais aplicadas que futuras pesquisas sobre as razões que motivam a escolha pela docência universitária podem trazer para as discussões sobre a formação profissional nesse contexto.

Como limites do estudo aponta-se que os dados foram coletados em apenas duas regiões do país, que embora sejam representativas, não nos permitem generalizar o resultado às demais regiões. Ressalta-se ainda que embora a EIFEE tenha obtido índices psicométricos satisfatórios, tal instrumento foi adaptado de um originalmente elaborado para a Educação Básica, em outra cultura, com currículos e modelos de formação diferentes. Nessa direção, é necessário cautela na interpretação desses resultados.

Por fim, é sugerido que futuras investigações sobre a escolha pela docência no Ensino Superior possam contemplar outros aspectos, como, por exemplo, o papel das regulações face à formação de futuros docentes. Os estudos aqui apresentados representam apenas uma parte dessa discussão. Além disso, explorar outras abordagens metodológicas, como as que utilizam instrumentais de natureza qualitativa, associadas ao apresentado no presente estudo, poderia contribuir para o desvelamento de novas informações capazes de ampliar e promover a necessária e urgente discussão sobre a formação docente para o Ensino Superior.

\section{Referências}

Akar, E. O. (2012). Motivations of Turkish pre-service teachers to choose teaching as a career. Australian Journal of Teacher Education, 37(10), 66-84.

Alves, A. L., \& Enslin, L. (2008). Proposta para avaliação docente para os professores do curso técnico de telecomunicações do campus São José do Instituto Federal de Santa Catarina. Revista de Ensino de Engenharia, 31(1), 2-12.

Azzi R. G., \& Polydoro, S. A. J. (2006). Auto-eficácia em diferentes contextos. Campinas: Alínea.

Bandura, A. (1997). The Nature and Structure of Self-Efficacy. In Bandura, A. Self-efficacy: The exercise of control (pp. 36-78). New York: Freeman.

Bandura, A. (1997). Sources of Self-Efficacy. In Bandura, A. Self-efficacy: The exercise of control (pp. 36-78). New York: Freeman.

Bazzo, W. A., Pereira, L. T. V., \& Von Linsigen, I. (2000). Educação tecnológica: enfoques para o ensino de engenharia. Florianópolis: Editora da UFSC.

Bernardini, P. (2017). Estudo correlacional sobre autoeficácia e Burnout no trabalho docente no ensino superior. (Dissertação de Mestrado, Universidade do Oeste Paulista, Presidente Prudente, Brasil).

Brasil. Ministério da Educação. Coordenação de Aperfeiçoamento de Pessoal de Nível Superior. (2016). Relatório Final 2016 da Comissão Especial de Acompanhamento do Plano Nacional de Pós-Graduação - PNPG 2011-2020 / Coordenação de Pessoal de Nivel Superior. Brasília, DF: CAPES.

Cirani, C. B. S., Campanario, M. A., \& Silva, H. H. M. (2015). A evolução do ensino da pós-graduação senso estrito no Brasil: análise exploratória e proposições para pesquisa. Avaliação: Revista da Avaliação da Educação Superior (Campinas), 20(1), 163-187.

Corrêa, G. T., \& Ribeiro, V. M. B. (2013). A formação pedagógica no ensino superior e o papel da pós-graduação stricto sensu. Educação e Pesquisa, 39(2), 319-334.

Cunha, M. (2006). Docência na universidade, cultura e avaliação institucional: saberes silenciados em questão. Revista Brasileira de Educação, 11(32), 258-271. http://dx.doi.org/10.1590/s1413-24782006000200005

Dallabona, C. A., \& Alberti, M. E. (2016). Evasão e Retenção em Cursos de Engenharia: Busca de Respostas a Partir de Indicadores Acadêmicos. In Proceedings of XLIV Congresso Brasileiro de Educação em Engenharia - COBENGE, Natal, RN, Brasil. 
Heinz, M. (2015) Why choose teaching? An international review of empirical studies exploring student teachers' career motivations and levels of commitment to teaching. Educational Research and Evaluation, 21(3), 258-297.

IBM Corp. (2013). IBM SPSS Statistics for Windows, Version 22.0. Armonk, NY: IBM Corp.

Kilınç, A., Watt, H., \& Richardson, P. (2012). Factors influencing teaching choice in Turkey. Asia-Pacific Journal of Teacher Education, 40(3), 199-226.

König, J., \& Rothland, M. (2012). Motivations for choosing a teaching career: Effects on general pedagogical knowledge during initial teacher education. Asia-Pacific Journal of Teacher Education, 40, 289-315.

Lent, R. W., Brown, S. D., \& Hackett, G. (1994). Toward a unifying social cognitive theory of career and academic interest, choice, and performance [Monograph]. Journal of Vocational Behavior, 45, 79-122.

Longo, W. P. (2010). Reflexões de um engenheiro sobre ciência, tecnologia e educação. Revista de Ensino de Engenharia, $29(1), 40-50$.

Marini, T. (2013). A função do ensino e a formação do professor universitário. São Paulo: Paulus.

Masetto, M. T., \& Gaeta, C. (2013) O professor iniciante no Ensino Superior: aprender, atuar e inovar. São Paulo: Senac São Paulo.

Matos, M. M. (2015). Autoeficácia docente e escolha pelo ensino superior no contexto do estágio de docência em engenharia. (Dissertação de Mestrado, Universidade Estadual Paulista Júlio de Mesquita Filho, Rio Claro, Brasil). Retirado de: https://repositorio.unesp.br/handle/11449/134133

Pinto, D. P. \& Oliveira, V. F. (2010) Educação em engenharia como área do conhecimento. In: Pinto, D. P., Oliveira, V. F., \& Pereira, R. C (Orgs.). Educação em engenharia: evolução, bases, formação. Juiz de Fora: Ed. Fórum Mineiro de Engenharia de produção.

Polydoro S. A. J., Winterstein, P., Azzi, R. G., Carmo, A. P., \& Venditti Jr, R. (2004). Escala de Auto-eficácia do professor de educação física. Avaliação Psicológica: formas e contextos, 01, 330-337.

Postareff, L., Lindblom-Ylanne, S., \& Nevgi, A. (2007). The effect of pedagogical training on teaching in higher education. Teaching and Teacher Education, 23(5), 557-571.

Reis, C. A. C. (2009). As representações sociais de engenheiros-professores sobre a docência. (Dissertação de Mestrado, Centro Federal de Educação Tecnológica de Minas Gerais, Belo Horizonte, Brasil).

Richardson, P.W., \& Watt, H. M. G. (2006). Who chooses teaching and why? Profiling characteristics and motivations across three Australian universities. Asia Pacific Journal of Teacher Education, 34, $27-56$.

Rocha, M. S. (2009). A auto-eficácia docente no Ensino Superior. (Tese de Doutorado, Unversidade Estadual de Campinas, Campinas, Brasil)

Soares, S. R., \& Cunha, M. I. (2010). Programas de pós-graduação em educação: lugar de formação da docência universitária? Revista Brasileira de Pós-Graduação, 7(14), 577-604.

Tartuce, G. L. B. P., Nunes, M. M. R., \& Almeida, P. C. A. (2010). Alunos do ensino médio e atratividade da carreira docente no Brasil. Cadernos de Pesquisa [online]. 40(140), 445-477.

Tschannen-Moran, M., \& Woolfolk Hoy, A. (2001). Teacher Efficacy: Capturing an Elusive Construct. Teaching and Teacher Education, 17, 783-805.

Watt, H., \& Richardson, P. (2007). Motivational factors influencing teaching as a career choice: development and validation of the FIT-Choice scale. The Journal of Experimental Education, 75(3), 167-202. http://dx.doi.org/10.3200/ jexe.75.3.167-202

Watt, H., \& Richardson, P. (2012). An introduction to teaching motivations in different countries: comparisons using the FIT-Choice scale. Asia-Pacific Journal of Teacher Education, 40(3), 185-197. http://dx.doi.org/10.1080/13598 66x.2012.700049

Watt, H., \& Richardson, P. (2015). A motivational analysis of teacher's beliefs. In: Fives, H, \& Gil, M. G. (Eds.) International Handbook of Research on Teachers' Beliefs (pp. 191-211). Abingdon: Taylor \& Francis.

Recebido 01/02/2018

Reformulado 27/08/2018

Aceite Final 21/10/2018

\section{Sobre os autores}

Mayara da Mota Matos é Graduada em História pela Universidade Estadual Paulista (2008), Mestre em Educação pela Universidade Estadual Paulista (2015). Doutoranda em Educação no Instituto de Biociências, UNESP, Rio Claro. Membro do Núcleo de Estudos em Teoria Social Cognitiva e Práticas Educativas.

Roberto Tadeu Iaochite é Licenciado em Educação Física pela Universidade Estadual Paulista (1994), Mestre em Ciências da Motricidade pela Universidade Estadual Paulista (1999) e Doutor em Educação pela Universidade Estadual de Campinas (2007). É Professor Assistente Doutor no Departamento de Educação da UNESP, Rio Claro. Coordenador do Núcleo de Estudos em Teoria Social Cognitiva e Práticas Educativas. 